\title{
LIBERDADE ECONÔMICA E A REGULAÇÃO PUBLICITÁRIA NO ÂMBITO DO MUNICÍPIO DE NATAL/RN
}

\author{
José Anderson Souza de Salles ${ }^{69}$ \\ Vinicius Augusto Cipriano M. de Souza ${ }^{70}$
}

\begin{abstract}
RESUMO
Por meio de uma pesquisa teórico-descritiva, com a metodologia preconizada pela dogmática jurídica, o presente trabalho tem por objeto analisar as principais mudanças trazidas pela Lei de Liberdade Econômica e seus impactos na atividade fiscalizatória do município de Natal/RN em matéria de publicidade e propaganda. Haveria antinomia nas legislações confrontadas? Estaria a administração pública municipal incorrendo em abuso do poder regulatório de maneira a restringir o uso e o exercício da publicidade e propaganda sobre um setor econômico? O produto final deste trabalho é um estudo regional acerca da temática que servirá para a academia, para os gestores públicos e para os empreendedores locais identificarem se o Município estaria exorbitando de suas atribuições.
\end{abstract}

Palavras-chave: Lei de Liberdade Econômica. Regulação. Publicidade e propaganda. Custos de transação. Abuso de poder regulatório.

\section{INTRODUÇÃO}

Viabilizar a concretização das políticas públicas exige uma constante atualização do Direito Administrativo sob o aspecto da pluralidade de direitos e garantias que permeiam o texto constitucional e a convergência de interesses privados que, por vezes, são colidentes.

Como forma de assegurar e garantir a livre iniciativa, o bem-estar da coletividade e a segurança (art. $1^{\circ}$, inciso IV, e art. 170, ambos da CR) de forma eficiente (art. 37, caput, da CR), exige-se do Legislador a utilização do exercício de Poder de Polícia por meio de instrumentos infraconstitucionais (leis complementares, ordinárias e atos administrativos normativos) para sua efetivação.

\footnotetext{
${ }^{69}$ Advogado e Auditor de Controle Externo do TCE/RN. Mestrando em Direito pela Universidade Federal do Rio Grande do Norte - UFRN. Email: anderson.ssalles@ gmail.com.

${ }^{70}$ Advogado e Professor. Mestrando em Direito pela Universidade Federal do Rio Grande do Norte - UFRN. Email: viniciuscipriano.adv@gmail.com.
} 
Com esse escopo que se instituiu a Declaração de Direitos de Liberdade Econômica, Lei Federal $n^{\circ} 13.487$, de 20 de setembro de 2019, cujo teor estabeleceu garantias de livre mercado e alterou vários dispositivos normativos de diversos diplomas, a exemplo da Lei das Sociedades Anônimas, Lei dos Registros Públicos, Código Civil, Consolidação das Leis do Trabalho, Cadastro Informativo dos créditos não quitados de órgãos e entidades federais.

Entre outras providências que foram dadas, um de seus pontos de destaque é a norma contida no art. $4^{\circ}$, VIII, da referida Lei, que estabeleceu ser dever da Administração Pública evitar o abuso do poder regulatório de maneira a, indevidamente, restringir o uso e o exercício da publicidade e propaganda sobre um setor econômico, ressalvadas as hipóteses expressamente vedadas em lei federal; isto é, as limitações que não estejam amparadas em casos expressamente estabelecidos pela legislação federal.

A existência de uma infinidade de normas regulatórias sobre diversos setores, o poder de polícia municipal sobre poluição ambiental das cidades, somados a ausência de clareza quanto ao que é ou não admitido veicular nas propagandas, gera imprevisibilidade e, por consectário, insegurança jurídica para os agentes econômicos na hora de divulgarem os benefícios dos seus produtos e serviços.

Nesse sentido a Lei de Liberdade Econômica vem sendo bastante festejada, sob a expectativa de que o dispositivo mencionado acima tenha condições de garantir maior liberdade aos agentes econômicos no momento de anunciarem seus produtos. Entretanto se observa que a Lei se valeu de conceitos gerais em abundância, sem enfrentar os problemas concretos de um modo específico, o que pode conduzir o intérprete a criar regras jamais imaginadas pelo legislador, aumentando o ambiente de insegurança jurídica.

A questão central desta pesquisa diz respeito a relação dialógica a ser estabelecida entre a Lei de Liberdade Econômica com normas jurídicas que regem as atividades econômica, bem como o modo que se insere o poder regulatório na perspectiva federativa. A outro tanto, a sua aplicação em face das legislações municipais ganha um elemento adicional, uma vez que a publicidade urbana, abrangendo os painéis e letreiros expostos ao público sob qualquer modalidade, é assunto de peculiar de interesse do Município, e, como tal, fica sujeito à regulamentação e autorização da respectiva Prefeitura, que possui competência para policiar a afixação de anúncios no perímetro urbano e seus arredores. 
Assim, diante de eventuais incompatibilidades de prescrições das legislações confrontadas, além dos critérios de competência e da especialidade para a solução de antinomias aparentes, também caberá recorrer ao hierárquico - caso se entenda haver hierarquia entre lei federal e municipal - ou, ao menos, verificar eventual inconstitucionalidade decorrente da invasão, pelo legislador ordinário federal, de matéria reservada a lei municipal (SILVA, 2010).

Tendo em vista que o desenvolvimento urbano e a proteção estética das cidades são aspectos a serem analisados com a devida cautela, o recorte metodológico deste trabalho se resume a analisar os impactos da Lei de Liberdade Econômica na atividade fiscalizatória do município de Natal, no Estado do Rio Grande do Norte.

Nesse diapasão, empregar-se-á metodologia preconizada pela dogmática jurídica, tomandose por base uma perspectiva normativista do Direito, mas que reconhece a importância dos princípios jurídicos no sistema de Direito Positivo.

Apresentando os aspectos considerados mais relevantes do estudo elaborado, procurar-se-á responder, de forma concisa, os questionamentos levantados acima e identificar as principais mudanças trazidas pela novel legislação no que se refere à atividade fiscalizatória dos Municípios (alvarás de licenciamento publicitário), de forma a identificar a existência de eventuais contradições, na tentativa de auxiliar a gestão pública municipal a convergir estes interesses colidentes, fim precípuo de um Estado Democrático de Direito (art. 1º, da CR).

Considerando-se os custos de transação como sendo uma das espécies de falhas de mercado, ainda que entendidos como um subproduto de outras vícios de mercado existentes, torna-se imprescindível para o estudo do Direito, e aqui mais especificamente para a compreensão do contexto ao qual se insere a Lei de Liberdade Econômica, que se tenha a adequada compreensão da sua existência, do seu alcance e das consequências dessa inegável realidade, vez que se encontra presente em quase todos os contextos de negociação e intercâmbio que se estabelecem entre os indivíduos e agentes econômicos de modo geral.

Num segundo plano, portanto, deve-se observar se a atual regulação da publicidade e propaganda no município de Natal tem prejudicado o funcionamento do sistema de mercado, elevado os custos de transação, tornando menos eficientes do ponto de vista econômico, ou inviabilizando o exercício da atividade econômica local, de forma a se configurar em abuso de poder regulatório, previsto no artigo $4^{\circ}$ da Lei de liberdade econômica. 


\section{A LEI DE LIBERDADE ECONÔMICA E O CONFLITO APARENTE DE NORMAS EM MATÉRIA DE PUBLICIDADE E PROPAGANDA}

$\mathrm{Na}$ modernidade, o poder absoluto do rei moldava o Estado concentrando as atividades legislativas, executivas e judiciárias. Aos indivíduos restava a submissão e obediência a um poder não controlado.

Rompendo social e politicamente com o absolutismo, que barrava o progresso político e econômica da burguesia nascente e solapava as camadas mais carentes da sociedade, implantou-se o Estado Liberal, que resultou na construção de uma nova ordem jurídica.

Com o liberalismo exsurgiu o Estado de Direito e as primeiras Constituições, quais sejam, a francesa e a norte-americana. O constitucionalismo iniciou-se, assim, na limitação do poder político e sua legitimação com a finalidade de garantir as liberdades individuais (CANOTILHO, 2003).

As Constituições têm por finalidade conservar as conquistas incorporadas e avançar na direção de valores e bens jurídicos ainda não alcançados. Assim, Canotilho (2003) afirma que o Estado Democrático de Direitos se baseia na separação dos poderes e no ideal comum de subordinação do poder estatal à vontade dos cidadãos por meio de um documento escrito, no qual é declarado os limites do poder político e os direitos fundamentais do cidadão.

Nesse sentido, a principal finalidade dos direitos fundamentais é conferir aos indivíduos uma posição jurídica de direito subjetivo e, consequentemente, limitar a liberdade de atuação do Estado (DIMOULIS; MARTINS, 2018).

A partir desses direitos, ditos de liberdade contra o Estado, outros direitos foram sendo criados, de modo que o Estado passou a ter não só a obrigação de não intervir sobre os cidadãos, como também de atuar para o desenvolvimento pessoal e coletivo da sociedade.

De acordo com a perspectiva desenvolvimentista de Amartya Sen (2000), a contemporânea concepção constitucional de desenvolvimento supera questões restritas ao crescimento econômico. Para ele, a prosperidade de uma nação implica na transformação das estruturas sociais, econômicas e institucionais. Com efeito, pouco serviria ter garantido uma série de direitos fundamentais se não existisse uma rede de instituições para tutelar seu efetivo exercício. 
Nesse mesmo sentido Dimoulis e Martins (Apud Schimitt, 2018) ressaltam que a garantia de direitos é de responsabilidade de diferentes instituições, públicas e privadas, que atuam de acordo com suas competências, tais como, aparato eleitoral, tribunais, a própria Administração Pública, como também a família, a propriedade, a livre iniciativa.

A Constituição Federal de 1988, logo em seu artigo $1^{\circ}$, registra que a República Federativa do Brasil é formada pela união indissolúvel dos Estados e Municípios e do Distrito Federal e se constitui por um Estado Democrático de Direito, que tem por fundamento os valores sociais do trabalho e da livre iniciativa (Constituição Federal, art. $1^{\circ}$, IV).

Uma das faces da livre iniciativa é a liberdade econômica prevista no art. 170, parágrafo único, da Constituição Federal, a qual independentemente de autorização de órgãos públicos visa assegura a todos o livre exercício de qualquer atividade econômica, salvo nos casos previstos em lei (GRAU, 2010).

Como se sabe, a Constituição é composta, em sua grande parte, por normas do tipo princípios jurídicos. No que tange a disciplina econômica, seu artigo 170, registrou-se que a Ordem Econômica deve ser fundada na valorização do trabalho humano e na livre iniciativa em conformidade com os ditames da justiça social, tendo por finalidade assegurar uma existência digna pautado em princípios como o respeito à propriedade privada e livre concorrência.

A efetividade do princípio da livre concorrência é objeto da Lei n. 12.529/2011. Por sua vez o princípio da propriedade privada está consagrado no art. $5^{\circ}$, caput e XXII, da Constituição Federal de 1988, como direito fundamental, sendo um dos principais objetos do Código Civil, que é considerado o mais amplo direito real, integrando as faculdades de usar, gozar e dispor da coisa, bem como de reivindicá-la de quem injustamente o detenha (direito de sequela).

Porém, há princípios contidos no art. 170 que, ainda hoje, não foram objeto de efetividade por meio de normas de direito positivo. Sendo regulamentado, inicialmente, quando da edição da Medida Provisória que deu origem à Lei Federal n. ${ }^{\circ}$ 13.874, de 30 de abril de 2019, a livre iniciativa era um dos direitos fundamentais que não dispunham de concretude no plano legal.

É cediço que por diversas situações cotidianas da vida os princípios jurídicos colidem, gerando uma dificuldade ao intérprete com relação a qual direito deve prevalecer no caso concreto, o que contribui para uma crescente judicialização de direitos tidos como fundamentais.

Nesses casos, o Judiciário precisa identificar qual desses princípios possuem maior "peso" no caso particular, de forma que tem sido amplamente realizado no Brasil, pela doutrina e pelo 
Poder Judiciário, a técnica da ponderação e do princípio da proporcionalidade, com base na teoria do jurista alemão Robert Alexy (2015), como meio de solucionar problemas de colisão entre direitos fundamentais estruturados como princípios.

Sob esta ótica, quanto mais esses princípios tenham sido positivados, sendo objeto de concretude legal, maior será a probabilidade de sua prevalência na escala de peso do julgador, que intuitivamente ou discursivamente irá atribuir importância, pertinência e valor ao correspondente princípio.

Entretanto, consta que a aplicação da teoria desenvolvida por Alexy (2015) passou a carecer de maior rigor científico para não servir a meros subjetivismos do intérprete. Uma vez que um princípio passa a se concretizar por meio de norma no direito positivo, naturalmente influenciará o sopesamento destinado a superar o conflito entre os princípios. O que reduz a possibilidade de os julgadores se utilizarem do princípio da proporcionalidade para justificar uma escolha pessoal, sem a demonstração do raciocínio aplicado.

A experiência brasileira é abundante em casos como estes, inclusive no sentido de estabelecer normas que impõem custos de transação absolutamente desnecessários aos setores econômicos dos mais diversos ramos.

A título de exemplo podemos citar a tese com repercussão geral 967 do Supremo Tribunal Federal - STF, fixou o entendimento de que lei municipal que proíba ou restrinja a atividade de transporte por motorista cadastrado em aplicativo é inconstitucional, uma vez que viola os princípios da livre iniciativa e da livre concorrência.

No caso, a Câmara Municipal de São Paulo interpôs o recurso extraordinário $1054110^{71}$, contra acórdão do Tribunal de Justiça do Estado, que declarou a inconstitucionalidade da Lei municipal $n^{\circ} 16.279 / 2015$, sob o fundamento de que o serviço de transporte individual de passageiros tem natureza pública, o que pressupõe autorização do Poder Público sob pena de resultar em injusta competição com os serviços oferecidos por taxistas.

No caso em exame o relator, Ministro Luís Roberto Barroso registrou que o princípio da livre iniciativa não tem caráter absoluto, pois a ordem econômica constitucional é igualmente orientada por outros princípios que legitimam intervenções estatais na economia para correção de falhas de mercado e tutelar direitos dos consumidores. Ao sopesar a intensidade conferida, de um lado, ao princípio da livre iniciativa e, de outro lado, aos princípios de proteção ao consumidor e

\footnotetext{
${ }^{71}$ STF, Tribunal Pleno, RE 1054110, relator Min. Roberto Barroso, DJe. 05-09-2019.
} 
de repressão à concorrência abusiva, o Ministro relator entendeu que, salvo sob fundamento Constitucional, uma lei municipal não pode arbitrariamente retirar a liberdade de empreender das pessoas.

Nesse sentido, a Lei de Liberdade Econômica vem sendo bastante festejada, sob a expectativa de que possa garantir maior liberdade aos agentes econômicos. Entretanto, o que se observa é que a mencionada Lei não enfrentou os problemas concretos de modo específico, ao invés disso, utilizou-se de conceitos gerais em abundância, conduzindo o intérprete a criar regras jamais imaginadas pelo legislador e, por consequência, aumentando o ambiente de insegurança jurídica.

Analisando a problemática do presente estudo de forma sistemática, temos que o inciso I, do art. $4^{\circ}$, da Lei de Liberdade Econômica, a fim de assegurar a livre iniciativa, qualifica como abuso do poder regulatório "criar reserva de mercado ao favorecer, na regulação, grupo econômico, ou profissional, em prejuízo dos demais concorrentes". Por sua vez, o inciso V, do art. $4^{\circ}$, também caracteriza como abuso de poder regulatório "aumentar os custos de transação sem demonstração de benefícios".

Vale o registro de que tais normas já estavam previstas na lei de processo administrativo federal, Lei Federal n. ${ }^{\circ}$ 9.784/99, por meio de seu art. $2^{\circ}$, parágrafo único, inciso VI, ao exigir a "adequação entre meios e fins, vedada a imposição de obrigações, restrições e sanções em medida superior àquelas estritamente necessárias ao atendimento do interesse público".

Ainda tratando das Garantias de Livre Iniciativa, especificamente no inciso VIII, do Art. $4^{\circ}$, da Lei de Liberdade Econômica, chegamos a norma objeto de estudo do presente trabalho, que estabeleceu ser dever da Administração Pública evitar o abuso do poder regulatório que, indevidamente, resulte na restrição do uso e o exercício da publicidade e da propaganda sobre um setor econômico, ressalvadas as hipóteses expressamente vedadas em lei federal; isto é, as limitações que não estejam amparadas em casos expressamente estabelecidos pela legislação federal.

Ademais, importante considerar que o Direito, ao conformar as instituições, entre elas inclusive as estruturas dos mercados, pode aumentar ou mesmo reduzir os custos de transação, evidenciando que o Direito é fundamental para o desenvolvimento econômico. Nesse sentido, a Lei da Liberdade Econômica vai justamente no sentido da busca da melhoria do ambiente de negócios, sobretudo por meio da redução dos custos de transação. 
Exatamente nessa linha é que o dever imposto a administração pública, de se evitar o abuso do poder regulatório de maneira a, indevidamente, restringir o uso e o exercício da publicidade e propaganda sobre um setor econômico, ressalvadas as hipóteses expressamente vedadas em lei federal; isto é, as limitações que não estejam amparadas em casos expressamente estabelecidos pela legislação federal.

Nesse quesito se faz imperioso evidenciar que a abordagem do tema exige a fixação de premissa teórica à conceituação e diferenciação dos termos "publicidade" e "propaganda".

O Conselho Executivo das Normas-Padrão - CENP, entidade responsável por assegurar o emprego de boas práticas comerciais entre anunciantes, agências de publicidade e veículos de comunicação, entende que tal classificação não seja relevante, considerando que tanto publicidade como propaganda objetivam difundir ideias, porém na primeira está presente com maior acuidade a intenção de convencer ou estimular o destinatário da mensagem.

A Lei de Propaganda - Lei Federal n. ${ }^{\circ} 4.680 / 1965$ - é o diploma mais relevante para esta atividade, resultante de demandas dos agentes do referido setor, principalmente a partir das conclusões alcançadas durante o I Congresso Brasileiro de Propaganda. Em termos específicos, a norma define propaganda utilizando-se de alguns aspectos inerentes ao gênero a que esta pertence, ou seja, publicidade.

Dispõe a lei em seu artigo $5^{\circ}$, que a propaganda "compreende-se qualquer forma remunerada de difusão de ideias, mercadorias ou serviços, por parte de um anunciante identificado". Quanto à definição de publicidade, conforme se lê no art. $8^{\circ}$ do mesmo Código, consiste em "toda atividade destinada a estimular o consumo de bens e serviços, bem como promover instituições, conceitos ou ideias".

Apesar de serem conceitos distintos, cuja diferenciação é facilmente perceptível quando sob análise a etimologia das palavras, latente é, em ambas definições, a necessidade de levar ao conhecimento do consumidor algo que atenda aos interesses dos anunciantes, pois, em que pesem estes figurem em segundo plano, é impossível considerar a publicidade sem ter em mente os consumidores.

Não é diferente o que dispõe a doutrina especializada no assunto ao conceituar publicidade de acordo com os ditames do meio publicitário (SANT'ANNA, 1998, p.76):

Uma técnica de comunicação de massa, paga com a finalidade precípua de fornecer informações, desenvolver atitudes e provocar ações benéficas para os anunciantes, geralmente para vender produtos ou serviços. 
Em face das definições expostas, infere-se que a norma contida no inciso VIII, do Art. $4^{\circ}$, da Lei de Liberdade Econômica, em verdade, trata de dois temas no qual o controle de da de formas completamente diferente.

A propaganda, como uma técnica de comunicação de massa, é basicamente controlada sob o aspecto de seu conteúdo, de forma que não resultem no desrespeito de valores éticos da pessoa, da sociedade, nem que envolvam produtos que possam causar danos à saúde ou ao meio ambiente, de forma geral.

Norma constitucional que merece referência e reflete importante conquista do Estado democrático de direito é aquela contida no inciso IV de seu art. 5o: "é livre a manifestação do pensamento, sendo vedado o anonimato". Isto é, censura só é aceitável se estiverem contrapostos outros direitos fundamentais. Assim, compulsando o texto constitucional, são encontradas diversas restrições a propagandas, como aquelas que desrespeitam valores éticos da pessoa (art. $220,3^{\circ} \mathrm{e}$ art. 221, IV) e as que envolvam produtos danosos à saúde ou ao meio ambiente. Esse é o teor do $\S$ $4^{\circ}$ do artigo 220 da $\mathrm{CF}$, o qual se transcreve:

$\S 4^{\circ}$ A propaganda comercial de tabaco, bebidas alcoólicas, agrotóxicos, medicamentos e terapias estará sujeita a restrições legais, nos termos do inciso II do parágrafo anterior, e conterá, sempre que necessário, advertência sobre os malefícios decorrentes de seu uso.

Por outro lado, o controle da propagação de informações, principalmente quando se dá por meio de cartazes, banners, folhetos etc. é matéria que encontra guarida constitucional no Princípio da Proteção Ambiental, disposto no art. 225 da Carta Magna, como parâmetro de interpretação principiológica do regime de repartição de competências ambientais.

Do mesmo modo, em matéria de distribuição de competências constitucionais urbanísticas a Constituição da República atribui competência exclusiva da União (art. 21, IX e XX), aos Municípios (art. 182) e para os Estados, reconhecendo a todos eles competências concorrentes (art. 24, I), comum (art. 23, IX) e suplementar (art. 30, VIII).

A Constituição alerta para uma situação jurídica peculiar que reveste as competências urbanisticas e ambientais, a saber: deve-se adaptar a tradicional repartição de competências com $o$ modus operandi que reveste a proteção cooperada, onde não existe assunto o qual seja do interesse de um ente federativo, e não seja dos demais. 


\section{JURISDIÇÃO CONSTITUCIONAL: HIERARQUIA DE NORMAS OU REPARTIÇÃO DE COMPETÊNCIAS?}

Na doutrina jurídica, nenhuma norma deve ser interpretada de forma isolada, mas sempre de forma integrada com outras, de modo a retirar-lhe uma concepção concernente com o todo orgânico que é o ordenamento jurídico (BOBBIO,1999).

A ideia deste ordenamento enquanto sistema na qual resta presente uma estrutura composta por elementos racionais e uma lógica que determina o seu funcionamento, que se supõe uma ordenação interior e unidade de sentido, constitui um importante elemento agregado ao estudo da hermenêutica e aplicação do direito (GRAU, 2008).

Nesse sentido, a resolução de conflito aparente de normas no sistema de direito positivo brasileiro deve ter por base, inicialmente, o estudo da estrutura hierárquica das normas jurídicas, a mais importante contribuição de Kelsen à ciência jurídica, que tanto influenciou o pensamento jurídico ocidental, principalmente após a segunda guerra mundial (1999). De tal apresentação, surgiu a ideia do "Escalonamento Jurídico de Kelsen", que tem a Constituição em seu topo, constituindo o fundamento de validade das demais normas jurídicas.

Com o silogismo conhecido por "pirâmide de Kelsen", uma vez que as normas jurídicas inferiores retiram o fundamento de validade das normas superiores, o sistema jurídico passa a funcionar com a Constituição sendo o fundamento de validade de todas as normas, de modo que as denominadas infraconstitucionais não podem se opor à Constituição (KELSEN, 1999).

Em outras palavras, o fundamento de validade de uma norma apenas pode ser a validade de uma outra norma. Neste sentido, uma norma que representa o fundamento de validade de uma outra norma é figurativamente designada como norma superior, por confronto com uma norma que é, em relação a ela, a norma inferior. Esta norma superior confere à personalidade legiferante "autoridade" para estatuir normas. O fato de alguém ordenar seja o que for não é fundamento para considerar o respectivo comando como válido, ou seja, para ver a respectiva norma como vinculante em relação aos seus destinatários. Apenas uma autoridade competente pode estabelecer normas válidas; e uma tal competência somente se pode apoiar sobre uma norma que confira poder para fixar normas.

Convém anotar que a Constituição Federal legitima a intervenção do Estado, tanto no domínio econômico como no domínio social, para a efetivação das metas constitucionais de justiça 
social mediante a formulação e execução de políticas públicas (FRANÇA, 2009; e FRANÇA, 2014).

A Constituição Federal é quem positiva os valores que devem ser considerados com os mais fundamentais do ordenamento jurídico vigente no Brasil, a serem obrigatoriamente levados em consideração da intepretação e aplicação das normas e modelos jurídicos (REALE, 1999).

A identificação do poder habilitado para editar a norma jurídica, assim como do procedimento a ser empregado ao exercê-lo, passa necessariamente na compreensão das fontes do Direito. São elas que viabilizam a existência dos modelos jurídicos que, por sua vez, compõem o ordenamento jurídico (REALE, 1999). Entenda-se por modelo jurídico "a estrutura normativa de atos e fatos pertinentes unitariamente a dado campo da experiência social, prescrevendo a atualização racional e garantida dos valores que lhes são próprios" (REALE, 1999, p. 48).

Recorde-se que cabe à Constituição instituir o Estado e as relações entre este e as pessoas (BONAVIDES, 2002). O sistema de governo, a forma de Estado, a forma de governo, a organização dos poderes, os direitos fundamentais, enfim, todos os modelos jurídicos fundamentais e estruturantes de todo o ordenamento jurídico (REALE, 1999).

Para Kelsen (1999), as espécies normativas primárias são as que integram o processo legislativo constitucional, ou seja, as emendas constitucionais, leis complementares, leis ordinárias, leis delegadas, medidas provisórias, decretos legislativos e resoluções ${ }^{72}$.

Uma vez que a Constituição Federal é o fundamento de validade de todas as demais normas, há de se reconhecer a relação de hierarquia entre ela e as constituições dos estados membros, bem como entre as constituições estaduais e as leis orgânicas dos Municípios que compõem determinado estado.

Nesse interim, a distinção entre as espécies normativas é fixada pela Constituição mediante a reserva de matérias, não havendo que se falar em hierarquia entre cada uma das espécies normativas citadas. Ademais, por força do princípio da simetria constitucional, também se infere que não existe hierarquia entre as normas oriundas de diferentes entes da federação brasileira.

\footnotetext{
${ }^{72}$ Kelsen ainda faz a diferenciação entre lei e decreto. Ele os considera como subdivisões do escalão da produção de normas gerais. Em regra, as leis são produzidas por um parlamento, porem a Constituição permite que em certos casos excepcionais o governo ou determinado órgão administrativo editem normas gerais. Estas normas que não são oriundas do parlamento são denominadas de decretos, que ainda podem ser regulamentares ou decretos-leis. Juntamente com as leis, os costumes e os decretos, as jurisprudências compõem o patamar das normas gerais da pirâmide kelseniana.
} 


\section{SOLUÇÃO DE CONFLITOS NORMATIVOS EM MATERIA DE ORDENAÇÃO DA PAISAGEM URBANA}

Uma vez reconhecida a autonomia política que os entes federados possuem no exercício de suas competências legislativas constitucionais, não havendo que se falar superioridade de lei federal em face da lei estadual ou municipal, passamos ao estudo do caso de conflito entre normas que envolvam interesses urbanísticos, e sua prevalência, num contexto de regras de competência fixadas pelo texto constitucional.

Em se tratando do domínio de vigência de uma norma, Kelsen afirma este é elemento de seu conteúdo, e que este conteúdo pode ser predeterminado até certo ponto por uma norma superior. Já o domínio pessoal de validade de uma norma, segundo este jurista, refere-se ao elemento pessoal da conduta fixada pela norma. Este domínio de validade pode ser limitado ou ilimitado (1999).

Sob o ponto de vista dogmático, as normas urbanísticas, por serem de direito público, são compulsórias, cogente, e de um modo específico, são de direito público, mais precisamente porque regulam (regram, normatizam, impõem modo de agir) uma função pública - que é a atividade urbanística do Poder Público conformando, por outro lado, a conduta e as propriedades dos particulares a seus ditames (SILVA, 2010).

A Constituição Federal emprega as expressões: (a) "planos nacional e regionais de ordenação do território", para a União (art. 21, IX); (b) "plano diretor", para os Municípios (art. 182). Não menciona planos urbanísticos para os Estados, embora reconheça a eles competência (concorrente) em direito urbanístico (art. 24,1).

Assim, o fundamento constitucional para elaborar executar o plano urbanístico nacional está no já citado art. 21, IX, onde se confere à União a competência para elaborar e executar o plano nacional de ordenação territorial, assim como o plano nacional de desenvolvimento econômico e social (também art. 174; Estatuto da Cidade, art. 4, a, I). Surge a questão de saber se ele deve constituir um plano específico de urbanismo, ou se se apresentará como parte do plano nacional de desenvolvimento econômico e social.

O plano urbanístico nacional constitui o conjunto de diretrizes gerais destinadas a instrumentalizar a política nacional do desenvolvimento urbano, ou conjunto coerente de medidas 
destinadas a estabelecer a orientação geral da ordenação territorial do país em função do bem-estar da população.

O conteúdo de um plano urbanístico nacional, como de qual quer outro, não pode ser fixado a priori. Há de decorrer de diagnóstico do sistema urbano brasileiro no momento da elaboração do plano e das perspectivas que se apresentam ao planejador. Assim mesmo é possível cogitar do conteúdo de um plano urbanístico nacional, que, no mínimo, DEVE compreender: (1) o diagnóstico básico; (2) a estratégia geral; (3) a estratégia específica; (4) relatórios e mapas (SILVA, 2010).

Por outro lado, a Constituição Federal prevê a competência da União para elaborar e executar planos regionais de ordenação territorial (artigo 21, IX). Aí se acha, pois, o fundamento constitucional para o estabelecimento e a execução do que temos chamado de "planos urbanísticos macrorregionais", porquanto são planos supraestaduais, abrangentes, em regra, de área geográfica correspondente a uma região geoeconômica, sob controle de uma superintendência de planejamento regional — SUDENE (extinta), SUDAM, SUDESUL ou SUDECO. O Plano urbanístico macrorregional é o instrumento do processo de ordenação territorial destinado a orientar a ocupação urbana do solo no nível das macrorregiões (SILVA, 2010).

Nesse interim, há aspectos setoriais em que a atuação da União é mais concreta, porque se trata de matéria de sua alçada, como é exemplo sua competência - expressamente estabelecida na Constituição Federal - para estabelecer o plano nacional de viação e para estabelecer e executar planos nacionais de saúde, no que se incluem planos de defesa do meio ambiente.

Os planos de preservação ambiental podem (e devem) ser estabelecidos pela União, inserindo-se, assim, na qualificação de planos urbanísticos setoriais federais. A primeira preocupação sistematizada, planejada, nesse sentido constituiu as diretrizes incluídas no Capítulo IX do II PND, como um aspecto da política do desenvolvimento urbano.

A partir daí tomaram-se várias providências legislativas e administrativas visando à proteção ambiental, especialmente pela instituição da política nacional de meio ambiente e do sistema nacional do meio ambiente pela Lei 6.938/1981, e a produção de ampla legislação especial de proteção ambiental, federal, estadual e municipal.

Por sua vez, o Estatuto da Cidade é mais completo, pois prevê entre os instrumentos da política urbana: (a) planos nacionais e regionais de ordenação do território e de desenvolvimento econômico e social; (b) planos estaduais de ordenação do território e de desenvolvimento econômico e social; (c) planos metropolitanos; (d) plano diretor municipal. Mas o Estatuto nada 
mais estabelece sobre os planos urbanísticos nacionais, regionais ou metropolitano. Só cuida do planejamento e do plano diretor municipal.

Entretanto, talvez por não ter atentado para essa natureza pública das normas urbanísticas é que o legislador do Estatuto da Cidade declarou que são "normas de ordem pública e de interesse social'.

Em essência, revela o objeto dos planos, e até se pode dizer que se harmoniza com a expressão "política de desenvolvimento urbano", que se acha no art. 182 da CF/88. Mas é certo que ela não caracteriza com a devida precisão a qualificação urbanística dos planos. Mas, se todos são instrumentos de ordenação do território, nisso se manifesta seu sentido urbanístico (MEIRELLES, 2008).

A denominação que vimos empregando já denuncia nossa posição: "plano urbanístico nacional" - que revela tratar-se de plano que visa a aplicar nacionalmente os princípios do urbanismo, com o objetivo de definir a orientação geral da organização urbana do território nacional (SILVA, 2010).

As leis orgânicas dos Municípios conferem competência a estes para regulamentar, autorizar e fiscalizar a afixação de cartazes e anúncios, bem como a utilização de quaisquer outros meios de publicidade e propaganda nos locais sujeitos ao poder de polícia municipal. Mesmo quando a lei orgânica não o faça, essa competência é municipal, por força do art. 30, I, da CF de 1988, por se tratar de assunto de interesse local.

Cabe ao Município a proteção estética da cidade, e para tanto pode e deve policiar a afixação de anúncios no perímetro urbano e seus arredores. A publicidade urbana, abrangendo os painéis e letreiros expostos ao público sob qualquer modalidade, é assunto de peculiar interesse do Município, e, como tal, fica sujeita à regulamentação e autorização da Prefeitura. A ação cominatória é adequada para o Poder Público compelir o particular a desfazer painel de propaganda afixado sem autorização municipal, ainda que localizado na propriedade privada.

Nesse contexto, quando os interesses em jogo se referem a regulação urbanística e uma vez reconhecida a inexistência de hierarquia entre as normas oriundas de diferentes entes da federação brasileira, inferimos que a problemática deve ser dirimida com um estudo sistemático da repartição de competências constitucionais nos moldes estabelecidos pela CF/1988. Assim, ante um eventual conflito, a lei que prevalecerá será aquela oriunda do ente federado competente para o tratamento da matéria. 


\section{ORDENAÇÃO DA PAISAGEM URBANA NO MUNICÍPIO DE NATAL/RN}

No Município de Natal/RN, a ordenação do mobiliário urbano paisagístico é justamente aquela que mais tem recebido regulamentação jurídica.

O desenvolvimento desordenado de anúncios de publicidade na paisagem urbana ocasiona evidentes prejuízos à estética da cidade e à segurança dos munícipes, e realçam a conveniência de assegurar a disposição equilibrada dos anúncios, em harmonia com as mensagens transmitidas e, como se trata também de problema técnico, o terceiro considerando justifica a necessidade da criação de um órgão permanente com atribuições especiais à constante atualização da legislação específica, em harmonia com as novas exigências técnicas e a realidade prática (MEIRELLES, 2008).

Em matéria urbanística no âmbito do município de Natal, no Estado do Rio Grande do Norte, criou-se o Conselho de Planejamento Urbano do Município de Natal - CONPLAN, instituído pelo Decreto n. ${ }^{\circ}$ 1.335/1973, que integra a Secretaria Municipal de Planejamento e Coordenação Geral.

O CONPLAM, em conjunto com a Secretaria da Habitação e Desenvolvimento Urbano (SEMURB) do Município, basicamente se destinam a ordenar a estética da cidade, o que revela preocupação que há muito não se encontrava na cogitação do Poder Público, que historicamente tem cuidado da regulamentação de anúncios mais preocupado com sua renda tributária, por meio da cobrança das taxas de licença, que com o aspecto urbanístico.

Por meio da Lei $n^{\circ} 3.175 / 1984$, foram definidas as atribuições e a composição atual do Conselho. O atual regimento interno do CONPLAM foi instituído pelo Decreto 3.075/1985. Já a denominação do Conselho Municipal de Planejamento e Meio Ambiente - CONPLAM foi alterada pela Lei Orgânica do Município, promulgada em 03 de abril de 1990. Por fim, deve-se registrar que com a promulgação do Código do Meio Ambiente do município, Lei n 4.100/92, as atribuições do Conselho foram ampliadas.

Nesse sentido, no âmbito do Município de Natal/RN, vigora até os dias atuais o Decreto Municipal no 4.621/1992, que impõe limites e regulamenta as formas de publicidade ao ar livre, dispondo acerca dos elementos que compõem a paisagem urbana, visando ao atendimento do 
interesse público, em consonância com os direitos fundamentais da pessoa humana e as necessidades locais de conforto ambiental, com a melhoria da qualidade da vida urbana, assegurando, entre outros, o bem-estar estético, cultural e ambiental da população; a percepção e compreensão dos elementos referenciais da paisagem; preservação da memória cultural etc. Tal Decreto se dedica especialmente à ordenação dos anúncios.

Por outro lado, a eficácia na manutenção e preservação da cidade em condições de limpeza é instituído pelo Código Municipal de Meio Ambiente (Lei no 4.100/1992) e, em alguns casos, pela Lei $n^{\circ} 4.748 / 1996$, que regulamenta a limpeza urbana no município.

Ademais, todo e qualquer agente econômico que queira divulgar seus produtos ou serviços aos consumidores devem recolher a taxa de licença para publicidade municipal. De modo que é de competência da Prefeitura do Município de Natal, através da SEMURB, orientar, fiscalizar e licenciar os anúncios de publicidade.

A partir da publicação do Decreto n ${ }^{\circ}$ 4.621/1992, a exploração e utilização de anúncios ao ar livre por meios tais como placas, faixas tabuletas, muros, fachadas e similares, inclusive mobiliário urbano, a partir desta data passa a ser disciplinada pelo presente decreto (art. $1^{\circ}$ ), de forma que todos os meios de publicidade devem estar previamente cadastrados em sistema particular do Município, denominado de IPLANAT (art. $2^{\circ}$ ), para serem veiculáveis.

Para o Decreto (art. $4^{\circ}$ e seguintes), anúncio é qualquer mensagem ou comunicação visual presente na paisagem urbana do município, em locais públicos ou privados, desde que visível do logradouro público. Dessa forma, os anúncios são classificados em indicativos, identificadores, propagandísticos, mistos e cooperativos.

Quanto à luminosidade, os anúncios são classificados como luminosos, iluminados e nãoluminosos. Para o referido Decreto, são luminosos os anúncios cuja mensagem é obtida por meio de emissão de luz oriunda de dispositivo luminoso próprio; iluminados, os meios cuja visibilidade de mensagem é reforçada por dispositivo luminoso externo e; não-luminosos os anúncios cujos meios de mensagem não possuem dispositivos de iluminação.

No que diz respeito as bases de anúncios, o Decreto prevê, restritivamente, que eles podem ser sustentados por meio de bases pré-existentes, como muros, fachadas, tapumes, toldos e em mobiliário urbano em geral. Da mesma forma, o Decreto já previa que os anúncios poderiam ser exibidos através de engenhos como cartaz mural ou outdoor, tabuleta, projetores, amplificadores, 
provisórios ou engenhos especiais, dos quais têm a propensão de causar riscos à segurança da população, ou que apresentem, pelo menos, uma das características listadas no art. 31 do Decreto.

Os anúncios podem ser submetidos a restrições de várias ordens, tanto em relação a zona de uso, como quanto ao local de sua exposição, relativamente a imóvel edificado ou a imóvel nãoedificado. Disso decorrem os conceitos de quota de anúncio, recuo de anúncio, área de exposição do anúncio, visibilidade do anúncio, altura do anúncio etc.

Em geral, as restrições e regulamentações variam de acordo com as peculiaridades de cada cidade. Mas, em geral, são proibidos anúncios, em qualquer zona, nos seguintes casos: (a) ao longo das vias de tráfego de elevado nível (vias expressas); (b) nos monumentos públicos e em suas proximidades, de modo a não prejudicar sua visibilidade (dos monumentos); (c) nos bens e locais tombados e em suas proximidades, de modo a não prejudicar sua visibilidade; (d) nas pontes, viadutos, passarelas; (e) sobre as árvores de vias públicas; (f) sobre postes, torres ou qualquer estrutura destinada a suportar as redes aéreas dos meios de comunicação e de energia elétrica; $(\mathrm{g})$ em qualquer parte dos cemitérios; (h) nas proximidades de semáforos, sempre que possam confundir sua visão ou interpretação (SILVA, 2010).

No que diz respeito as restrições no Município de Natal/RN, estas podem chegar à proibição de anúncios em determinadas zonas de uso, em determinados locais, logradouros, objetos e outros descritos no art. 40 do Decreto em comento.

Por tudo isso é que a colocação de anúncios na paisagem urbana fica sujeita ao controle da Prefeitura, que disciplina os limites de sua exploração e utilização, sua forma de apresentação, sua dimensão, sua posição (quota, recuo, altura etc.), exigindo-se que OS projetos sejam previamente aprovados pela SEMURB, e sua exploração ou utilização dependentes de prévia autorização municipal.

Os elementos de sinalização urbana, que não devem ser confundidos com anúncios indicativos, são constituídos de: (a) sinalização de trânsito; (b) nomenclatura de logradouros públicos; (c) numeração de edificações; (d) informações cartográficas da cidade. A sinalização de trânsito classifica-se em sinalização de advertência, sinalização indicativa e sinalização de regulamentação (SILVA, 2010).

Nos termos do art. 49, do Decreto em estudo, a inserção de publicidade no espaço urbano só será admitida quando reverter em efetivo benefício à comunidade, cabendo ao CONPLAM fixar 
normas técnicas (publicadas em forma de resolução) para a exploração e utilização de anúncios ao ar livre, por meio de placas, faixas, tabuletas e similares (art. 50).

A poluição visual, nos termos da regulação da paisagem urbana, é conceituada no art. 48, do Código Municipal de Meio Ambiente (Lei no 4.100/1992), como a alteração adversa dos recursos paisagísticos e cênicos do meio urbano e da qualidade de vida de sua população, mediante o uso abusivo ou desordenado de meios visuais.

Já a Lei n 4.748, de 30 de abril de 1996, que regulamenta a limpeza urbana do município de Natal, em seu art. 50 e incisos, estabelece que constituem atos lesivos à conservação de limpeza urbana, por exemplo, distribuir manualmente em logradouros públicos, edifícios comerciais e similares, papéis, volantes, panfletos, comunicados, avisos, anúncios, reclames e impressos de qualquer natureza, bem como afixar publicidade ou propaganda de qualquer natureza divulgada em tecido, plástico, papel ou similares; em postes, árvores de áreas e logradouros públicos em geral, mesmo quando propriedade privadas, mesmo que favorecidas pela publicidade ou propaganda, exceto as autorizadas pelas lei e regulamentos vigentes.

Nos termos do parágrafo único, do mesmo art. 50, a inobservância de tais normas sujeita os agentes economicos e seus mandantes a cominação das sanções previstas nos artigos 69 a 78 do mesmo código, de forma que, além de advertências e multas previstas, o município pode cominar penas que resultam na interdição de equipamentos até a suspensão ou cancelamento de registro de fabricantes instalados e conservadores e seus equipamentos.

Nesse interim, toda a propaganda e publicidade levada a efeito no Município de Natal/RN, por quaisquer instrumentos de divulgação ou comunicação, inclusive as que contiverem apenas dizeres, desenhos, siglas, dísticos ou logotipos indicativos ou representativos de nomes, produtos, locais ou atividades, mesmo aqueles fixados em veículos, estão sujeitas à prévia licença da Prefeitura e ao pagamento antecipado da Taxa de Licença de Publicidade.

Nesse sentido, uma das hipóteses suscitadas, sobretudo com base na Análise Econômica do Direito, é que quanto mais elevados são os custos de transação, mais difícil é empreender, seja para produzir ou mesmo ofertar serviços, comprometendo, assim, a performance econômica local.

O que se observou, de fato, é um excesso de burocracia e regulação no âmbito do Município de Natal/RN, que representam altos custos para se empreender e se fazer circular riquezas, engessando a economia e mesmo constituindo desestimulo para o empreendedor local. $\mathrm{O}$ que se 
requer, indiscutivelmente, a promoção de avanços e aperfeiçoamentos no que diz respeito à facilidade para a realização de negócios.

Cada Município ordena esses elementos como melhor lhe parecer e de acordo com a estrutura da cidade e condições financeiras. Com efeito, o Município de Natal/RN regulamentou esses elementos marcantes na paisagem urbana por meio de um ato normativo (decreto) que vigora a mais de vinte anos, influindo consideravelmente na estética e desenvolvimento econômico da capital potiguar.

O direito pode servir para, entre outros objetivos, facilitar e promover o funcionamento do sistema de mercado, corrigindo as denominadas falhas de mercado e, entre elas, os indigitados custos de transação.

Entretanto, a partir da análise das legislações que compõe a ordenação paisagística do Município de Natal/RN, percebe-se que os elevados custos de transação observados no Município prejudicam o funcionamento do sistema de mercado, tornando o mercado local menos eficiente do ponto de vista econômico, seja reduzindo os excedentes econômicos, seja mesmo, na margem, inviabilizando o exercício de algumas atividades econômicas que queiram divulgar seus produtos e serviços aos consumidores.

Sem a admissão e ponderação dos custos de transação que são criados pelo abuso do poder regulatório torna-se improvável ou até mesmo impossível fomentar a iniciativa privada. Portanto, a baixa eficiência econômica atualmente experimentada no mercado local poderia, pelo menos em boa medida, ser explicada pelos elevados custos de transação observados.

Tal conclusão também se insere na compreensão de que o sistema regulatório pode conformar mecanismos de incentivos responsáveis por estimular ou até mesmo desestimular o empreendedorismo, a produção de bens, a prestação de serviços e a realização de transações econômicas e consequentemente o crescimento e o desenvolvimento econômico.

\section{CONSIDERAÇÕES FINAIS}

A presente pesquisa teve por finalidade analisar as principais mudanças trazidas pela Lei de Liberdade Econômica e seus impactos na atividade fiscalizatória do município de Natal/RN em matéria de publicidade e propaganda. 
Buscou-se, principalmente, examinar se haveria antinomia nas legislações confrontadas e se a administração pública municipal estaria incorrendo em abuso do poder regulatório de maneira a restringir o uso e o exercício da publicidade e propaganda sobre um setor econômico.

A pesquisa foi desenvolvida sob uma metodologia preconizada pela dogmática jurídica, tomando-se por base uma perspectiva normativista do Direito, mas que reconhece a importância dos princípios jurídicos no sistema de Direito Positivo.

Nesse contexto, a título de considerações finais e procurando responder, de forma concisa, os questionamentos levantados, alguns aspectos mais relevantes do estudo elaborado merecem ser destacados.

Inicialmente, se fez importante considerar que o Direito, ao conformar as instituições, entre elas inclusive as estruturas dos mercados, pode aumentar ou mesmo reduzir os custos de transação, evidenciando que o Direito é fundamental para o desenvolvimento econômico. Assim, a Lei da Liberdade Econômica vem sendo fundamental na busca de melhoria do ambiente de negócios, sobretudo por meio da redução dos custos de transação.

Por este lado, a Lei de Liberdade Econômica vem sendo bastante festejada sob a expectativa de que possa garantir maior liberdade aos agentes econômicos. Entretanto o que se observou é que a Lei não atacou os problemas concretos de modo específico, ao invés disso, valeu-se de conceitos gerais em abundância, o que pode conduzir o intérprete a criar regras jamais imaginadas pelo legislador, aumentando o ambiente de insegurança jurídica.

O que se requer, indiscutivelmente, é a promoção de avanços e aperfeiçoamentos no que diz respeito à facilidade para a realização de negócios.

Analisando a problemática do presente estudo de forma sistemática, temos que o inciso I, do art. $4^{\circ}$, da Lei de Liberdade Econômica, a fim de assegurar a livre iniciativa, qualifica como abuso do poder regulatório "criar reserva de mercado ao favorecer, na regulação, grupo econômico, ou profissional, em prejuízo dos demais concorrentes”. Por sua vez, o inciso V, do art. 4º também caracteriza como abuso de poder regulatório "aumentar os custos de transação sem demonstração de benefícios".

Ainda tratando das Garantias de Livre Iniciativa, especificamente no inciso VIII, do Art. $4^{\mathrm{o}}$, da Lei de Liberdade Econômica, chegamos a norma objeto de estudo do presente trabalho, que estabeleceu ser dever da administração pública evitar o abuso do poder regulatório que, indevidamente, resulte na restrição do uso e o exercício da publicidade e da propaganda sobre um 
setor econômico, ressalvadas as hipóteses expressamente vedadas em lei federal; isto é, as limitações que não estejam amparadas em casos expressamente estabelecidos pela legislação federal.

Uma vez reconhecida a autonomia política que os entes federados possuem no exercício de suas competências legislativas constitucionais, não havendo que se falar superioridade de lei federal em face da lei estadual ou municipal, passamos ao estudo do caso de conflito entre normas que envolvam interesses urbanísticos, e sua prevalência, num contexto de regras de competência fixadas pelo texto constitucional.

Conforme visto, quando os interesses em jogo se referem a regulação urbanística a problemática deve ser dirimida com um estudo sistemático da repartição de competências constitucionais nos moldes estabelecidos pela CF/1988. Assim, ante um eventual conflito, a lei que prevalecerá será aquela oriunda do ente federado competente para o tratamento da matéria.

Nesse sentido, cabe ao Município a proteção estética da cidade, e para tanto pode e deve policiar a afixação de anúncios no perímetro urbano e seus arredores. A publicidade urbana, abrangendo os painéis e letreiros expostos ao público sob qualquer modalidade, é assunto de peculiar interesse do Município, e, como tal, fica sujeita à regulamentação e autorização da Prefeitura. A ação cominatória é adequada para o Poder Público compelir o particular a desfazer painel de propaganda afixado sem autorização municipal, ainda que localizado na propriedade privada.

Com efeito, o Município de Natal/RN regulamentou esses elementos marcantes na paisagem urbana por meio de um ato normativo (decreto) que vigora a mais de vinte anos, influindo consideravelmente na estética e desenvolvimento econômico da capital potiguar.

A partir da análise das legislações que compõe a ordenação paisagística do Município de Natal/RN, percebe-se que os elevados custos de transação observados no Município prejudicam o funcionamento do sistema de mercado, tornando o mercado local menos eficiente do ponto de vista econômico, seja reduzindo os excedentes econômicos, seja mesmo, na margem, inviabilizando o exercício de algumas atividades econômicas que queiram divulgar seus produtos e serviços aos consumidores.

Portanto, a baixa eficiência econômica atualmente experimentada no mercado local poderia, pelo menos em boa medida, ser explicada pelos elevados custos de transação observados. 
Por fim, consideramos que o produto final deste trabalho é um estudo regional acerca da temática que servirá para a academia, para os gestores públicos e para os empreendedores locais identificarem se o Município estaria exorbitando de suas atribuições.

\section{REFERÊNCIAS}

ALEXY, Robert. Colisão de direitos fundamentais e realização de direitos fundamentais no Estado de Direito Democrático. Revista de Direito Administrativo, Rio de Janeiro, v. 217, 2015.

BOBBIO, Norberto. A Era dos direitos. Trad. de Carlos Nelson Coutinho. Rio de Janeiro: Elsevier, 2004.

BOBBIO, Norberto. Teoria do ordenamento jurídico. Trad. de Maria Celeste Cordeiro Leite dos Santos. 10. ed. Brasília: UnB, 2006. [reimpressão]

CANOTIlHO, J. J. Gomes. Direito Constitucional e a Teoria da Constituição. 7. ed. Coimbra. Almedina, 2011.

DE MELlO, Celso Antônio. Curso de Direito Administrativo. 31. Edição. São Paulo/SP: Malheiros, 2014.

DE MELLO, Celso Antônio. Discricionariedade administrativa e controle jurisdicional. São Paulo, Malheiros Editores, 1992.

DE MELLO, Celso Antônio. Conteúdo jurídico do princípio da igualdade. 3 ed. São Paulo, Malheiros Editores, 1993.

ELALI, André. Tributação e Regulação Econômica: um exame da tributação como instrumento de regulação econômica na busca da redução das desigualdades regionais. São Paulo/SP: MP, 2007.

ELALI, André. Normas tributárias indutoras e intervenção econômica. Rio de Janeiro: Forense, 2005.

FRANÇA, Vladimir da Rocha. Invalidação Judicial da Discricionariedade Administrativa no Regime Jurídico-Administrativo Brasileiro. Rio de Janeiro/RJ: Forense, 2000.

FRANÇA, Vladimir da Rocha. Estrutura e motivação do ato administrativo. São Paulo, Malheiros Editores, 2007.

FRANÇA, Vladimir da Rocha. Agência Nacional do Petróleo, Gás Natural e Biocombustíveis - ANP. São Paulo: Atlas, 2015. 
FRANÇA, Vladimir da Rocha. Princípio da legalidade administrativa e competência regulatória no regime jurídico-administrativo brasileiro. Revista de informação legislativa, $v$. 51, n. 202, abr./jun. 2014. Disponível em: http://www2.senado.gov.br/bdsf/item/id/503034. Acesso em: 20 mar. 2020

FREITAS, Juarez. Direitos Fundamental à Boa Administração Pública, $3^{\text {a }}$ ed; SP, Malhieros, 2014.

GRAU, Eros Roberto. A Ordem Econômica na Constituição de 1988. 14 edição. São Paulo/SP: Malheiros Editores, 2010.

GRAU, Eros Roberto. O direito posto e o direito pressuposto. 8. ed. São Paulo/SP: Malheiros, 2011.

HAYEK, Friedrich A von. The constitution of liberty. Chicago: The University of Chicago Press, 1978.

KELSEN, Hans. Teoria pura do Direito. $3^{\text {a }}$ ed. Tradução de João Baptista Machado. São Paulo, Martins Fontes, 1991.

MARTINS, Ricardo Marcondes. Regulação administrativa à luz da Constituição Federal. São Paulo, Malheiros Editores, 2011.

MARTINS, Leonardo; DIMOULIS, Dimitri. Teoria geral dos direitos fundamentais. 6. ed. São Paulo: Atlas, 2018.

MEIRELLES, Hely Lopes. Direito Municipal Brasileiro. $16^{\text {a }}$ edição. São Paulo/SP: Malheiros, 2008.

MEIRELLES, Hely Lopes. Direito Administrativo Brasileiro. 35 a edição. São Paulo/SP:

Malheiros, 2009.

MENDONÇA, Fabiano. Agências Reguladoras: a regulação econômica na atual ordem constitucional brasileira. Natal: Fabiano André de Souza Mendonça, 2015.

MENDONÇA, Fabiano. Introdução aos Direitos Plurifuncionais: os direitos, suas funções e a relação com o desenvolvimento, a eficiência e as políticas públicas. Natal: 2016.

MIRANDA, Jorge. Manual de direito constitucional: constituição e inconstitucionalidade. Tomo II. 3. ed. Coimbra: Coimbra Editora, 1991.

PONTES DE MIRANDA, Francisco Cavalcanti. Tratado de Direito Privado: Parte geral. Introdução. Pessoas físicas e jurídicas. Atualização de Vilson Rodrigues Alves. Campinas, Bookseller, 1999, v. 1.

REALE, Miguel. Lições preliminares de direito. 26. ed. São Paulo: Saraiva, 2002. 
ROSS, Alf. Direito e justiça. Tradução de Edson Bini. São Paulo, Edipro, 2000.

SILVA, José Afonso da. Direito Urbanístico Brasileiro. $6^{\text {a }}$ edição. São Paulo/SP: Malheiros, 2010.

SILVA, José Afonso da. Curso de Direito Constitucional Positivo. 35 edição. São Paulo/SP: Malheiros, 2012.

SUNDFELD, Carlos Ari. Direito Administrativo Ordenador. São Paulo/SP: Malheiros, 1997.

SUNDFELD, Carlos Ari. Direito Administrativo para Céticos. São Paulo: Malheiros, 2012.

\title{
ECONOMIC FREEDOM AND ADVERTISING REGULATION IN THE SCOPE OF THE COUNTY OF NATAL/RN
}

\begin{abstract}
Through a theoretical-descriptive research, with the methodology recommended by legal dogmatics, the present work aims to analyze the main changes brought by the Economic Freedom Law and its impacts on the inspection activity of the municipality of Natal / RN in terms of advertising and advertising. Would there be antinomy in the legislation faced? Is the municipal public administration abusing regulatory power in order to restrict the use and exercise of publicity and propaganda about an economic sector? The final product of this work is a regional study on the theme that will serve for the academy, for public managers and for local entrepreneurs to identify if the Municipality is exorbitant from its attributions.
\end{abstract}

Keywords: Economic Freedom Act. Regulation. Advertising and marketing. Transaction costs. Abuse of regulatory power. 